\title{
Measuring well-being by a multidimensional spatial model in OECD Better Life Index framework
}

\author{
Salvatore Greco \\ Department of Economics and Business, University of Catania, \\ Portsmouth Business School, University of Portsmouth \\ Alessio Ishizaka \\ Portsmouth Business School, University of Portsmouth \\ Giuliano Resce \\ Italian National Research Council (CNR) \\ Gianpiero Torrisi \\ Department of Economics and Business, University of Catania, \\ Portsmouth Business School, University of Portsmouth
}

\section{Highlights}

- A multidimensional spatial model is proposed to evaluate multidimensional wellbeing

- The distance between countries profiles and individual's opinion is interpreted as loss of well-being

- Societal losses are negatively correlated to well-being and quality of democracy

- Multidimensional spatial model is a promising framework for well-being assessment 


\begin{abstract}
One of the most influential measures of multidimensional well-being, the Better Life Index, launched by OECD in 2011, contains a detailed overview of the social, economic, and environmental performances of different countries. Since its launch, a relevant number of empirical studies have been proposed on these data, but the role played by the distance between societal priorities and country-level performance in Better Life Index as well as in multidimensional well-being remains underexplored. We propose to address this issue by means of a multidimensional spatial model. We position the countries in the Euclidean Kdimensional space in which each dimension is a specific aspect of well-being, and we consider each individual's opinion on the same dimensions to calculate the personal optimal point. The distance between the optimal point of well-being and the actual observed point at individual level is the individuals' loss in well-being. We show that the societal loss at country-level is negatively related to the overall well-being and the main indices of quality of democracy. Based on the above evidence, we would argue that a multidimensional spatial framework represents a promising tool for the analysis of the whole class of multidimensional measures of well-being in which a group of individuals expresses the weights individually assigned to a set of dimensions within a pre-established range.
\end{abstract}

Keywords: Multidimensional Spatial Model; Well-Being; Better Life Index; OECD

JEL Codes: D78; H11; P16 


\section{Introduction}

There is a general consensus about the limits of the Gross Domestic Product (GDP) in the prediction of societal well-being. This point has been largely discussed in the literature (among others, UNDP, 1996; Fleurbaey, 2009; Stiglitz et al., 2010; Frey and Stutzer, 2010; Bleys, 2012; Fioramonti, 2013; Costanza et al., 2014; De Beukelaer, 2014; Coyle, 2014; Karabell, 2014; Costanza et al., 2016). UNDP (1996), in particular, identifies five main critical aspects related to the measurement of economic performance in terms of GDP growth: 'jobless growth', 'voiceless growth', 'ruthless growth', 'rootless growth', and 'futureless growth'. Building upon the ongoing criticism, an increasing number of multidimensional measures of well-being has been proposed by the main international institutions (Costanza et al. 2014; 2016). Among them, the Human Development Index launched by the UNDP in 1990, and the Better Life Index (BLI) proposed by the OECD in 2011 have gained momentum.

We propose to consider the multidimensional measures of well-being as points in a Euclidean multidimensional space. Undeniably, the actual positioning of countries in the aforementioned multidimensional space depends on both structural factors and on the policy mix designed and implemented by each country at various levels of government. The structural factors include the physical capital embodied in equipment and both public and private physical infrastructures, the level of education, workforce skills, attitude and managerial talent, the stock and the functioning of social capital (the level of trust, the extent of networking between agents), both the level and the exploitation of the available technology (Porter et al., 2000), and the quality of government (Charron et al., 2014). Undeniably, the quality of government affects the policy mix especially, to the case at hand, the fiscal side as well as shaping the set of legal intervention and regulatory practices governing business (Rothstein, 2011). Moreover, the different endowment of structural factors, in turn, contribute to the persistence of differences 
among economies through a process of cumulative causation (Veblen, 1919; Young, 1928; Myrdal, 1957; Kaldor, 1981).

One can argue that the former represents a common framework in which different policy makers could and do act. Therefore, under the assumption that citizens are aware of the limitations arising from the structural characteristics ${ }^{1}$ it makes sense to focus on the policy's effects in order to tackle differences in well-being as measured by multidimensional indices.

In economic theory, this point was partially addressed with the seminal contribution of Tiebout (1956) regarding the public services. By adapting Tiebout's structure to multidimensional wellbeing, we can assume that people/voters have their idea about the optimal proportions among the 11 topics included in BLI (people's mix of well-being), and that policy makers' activities are devoted in providing a specific policy boundle (policy maker's boundle of well-being). For instance, in the same country, there could be a relevant share of people interested in a specific aspect of well-being, such as health care, and at the same time, there could be policy makers who are improving education more than health ${ }^{2}$. In this context, since the objective function of the policy maker is to be (re-)elected, policy makers are supposed to act according to local preferences (Persson, Tabellini, 2002; Alesina, Giuliano, 2009). Moreover, according to a realistic imperfect knowledge setting in which the government is itself ignorant of what its citizens want it to do, the government has a rational incentive to proactively sound out the electorate and discover their desires and to persuade them it should be re-elected on the basis of its "conformity to popular desire" (Downs, 1957, p.140)

\footnotetext{
${ }^{1}$ At least in the sense that the structural factors affect the set of feasible points on the Utility Possibility Frontier (UPF). Therefore, citizens can well perceive the set of structural factors as constraint of their economy they share with their peers.

${ }^{2}$ Of course, the final outcome will depend also on the efficiency levels.
} 
This analysis proposes a methodological contribution to test to what extent people's preferences among the different dimensions of well-being match with the policy makers' supply, as measured in the OECD BLI framework.

From a normative standpoint, the multidimensional perspective of BLI is rooted in the theory of Rawls (1971), and in the capability approach proposed by Sen (1985). Unlike the welfarist approaches, which focus solely on the utility, in the capability approach both what people do and are (their functioning) and people's freedom to make life choices (their capabilities) matter (Durand, 2015). While the eleven metrics proposed in the BLI mainly refer to functioning (e.g., job and health status), people's freedom to make life choices involves their subjective priorities among the different dimensions. In other words, "the level of well-being of individuals with different preferences" (Stiglitz et al. 2010, p. 143) should be measured considering that people may attach varying importance to different dimensions (Helliwell, 2003; Helliwell, BarringtonLeigh, 2010; Decancq, Schokkaert, 2013). In this context, we propose to estimate to what extent people's priorities drive policy makers towards providing specific representations of multidimensional well-being.

A widely used model to study these phenomena is the spatial model of preferences (Bogomolnaia, Laslier, 2007). The multidimensional spatial models have been extensively used to study the electoral competition (Eguia, 2011), and to the best of our knowledge this is the first application in the context of multidimensional well-being. In a multidimensional spatial perspective, we consider the OECD countries as objects of preferences. In the BLI framework, the countries are points in the Euclidean K-dimensional space, in which each dimension is a specific aspect of well-being. Each individual/voter is characterized by her ideal point in that same space. For each individual the distance between its optimal mix of wellbeing, and the mix provided by policy makers can be interpreted as individual loss in wellbeing. In other words, the higher the distance between citizens' optimal mix and the mix 
provided by the policy maker, the lower the level of individual well-being. Therefore, the countries can be judged as good as they are close to the voters' ideal points.

There are two main reasons why the OECD BLI is particularly suitable for this kind of analysis. First, since it contains 24 variables related to 11 different topics, it is one of the largest dataset collecting well-being data at country level (Patrizii et al. 2017). Second, in the dedicated website (OECD, 2018), OECD provides a survey of the user weightings related to the 11 topics. Therefore, OECD currently has the most extensive survey about the subjective optimal mix (or ideal points) of well-being. Building upon this dataset, we propose to interpret the countrylevel citizens' individual weightings, as the optimal subjective mix of well-being, and we propose to interpret the country-level proportions among the performances in the topics, as the mix of well-being provided by policy makers, given the structural constraint. With these assumptions, we propose to assess empirically the country-level societal loss of well-being, by estimating, for each country included in the OECD survey, the distance between these mixes.

By means of four different specifications of societal loss functions at country level, we show that the societal loss due to the mismatching between the will of the people and policy makers' activity, is negatively related with the main indices of quality of democracy taken from the World Happiness Indicator (Helliwell et al. 2016), and from the Worldwide Governance Indicators (Kaufmann et al. 2011). Moreover, we show that countries with more mismatching are also countries with lower levels of Better Life Index.

The rest of the paper is organized as follows: Section 2 describes the Better Life Index and presents our dataset; Section 3 explains our multidimensional spatial model and our societal loss function; in Section 4 we show the results; Section 5 concludes. 


\section{The Better Life Index}

The BLI proposed by OECD in 2011 builds upon Stiglitz et al. (2010)'s claim that the wellbeing is multidimensional, and, therefore, it should be measured considering simultaneously more than one indicator. The BLI is composed by eleven topics, some of them measured with a single variable and some others measured with a simple average of two or more related variables. The Table 1 describes the composition, in terms of original variables, of each topic.

In the BLI original variables, there are positive (P), such as 'Rooms per person', and negative (N), such as 'Dwellings without basic facilities', measures of well-being (Table 1). Following the OECD procedure (OECD, 2018), the data originated from the 24 variables have been transformed according to the following procedures: (1) normalization called 'min max method' (Nardo et al. 2008), and (2) translation applied to negative variables (variables with $\mathrm{N}$ in Table 1):

(1) $\quad$ Norm $=\left(\frac{\text { observed value }- \text { minimum value }}{\text { maximum value }- \text { minimum value }}\right)$

(2) $\quad$ Index $=(1-$ Norm $)$

Since each topic of well-being is measured by one to four indicators (see Table 1), in line with the OECD guidelines (OECD, 2018), after normalisations in (1) and (2), topics composed by more than one indicator $(N \geq 2)$ are calculated as:

$$
\text { (3) } \operatorname{Topic}_{k}=\left(\frac{\sum_{i=1}^{N} \text { Index }_{i}}{N}\right), k=1, \ldots K
$$

The final database covers 36 Countries over 11 topics. The Table 1 summarises the descriptive statistics of the scores for each topic. 
As mentioned, for the purpose of our analysis we propose to measure the well-being in terms of the performance according to a bundle of dimensions. Consequently, we proceed with an additional normalization on the topics values:

$$
\text { (4) Norm_Topic } k=\left(\frac{\text { Topic }_{k}}{\sum_{k=1}^{K} \text { Topic }_{k}}\right), k=1, \ldots K
$$

in order for each country to have the same total amount of BLI. In other words, the formula (4) compute the relative contribution of each dimension to the overall value. So, these relative contributions sum to one across all dimensions. Put it differently, since each topic has been further normalised along the cross-section dimension, our distance measure does not depend on the total amount but rather it depends only on the mix of well-being (i.e. the proportions among the topics).

As mentioned, in the dedicate website, people can express their opinion on each topic by rating the topics according to their personal value judgment. The ratings are in a score that is in the interval $[0,5]$. For each of the person expressing their opinion, the website builds its own BLI, with an algorithm that estimates the weighted average of country level values of the topics (performances) multiplied by the subjective scores (value judgments). In this procedure, the score given to each topic is converted into a weight, by dividing the grade given to each topic by the sum of the grades given to all topics. For example, if a user assigns a score 5 to Health and Education and 3 to all the other topics, their Index will weigh health and education by a factor of $5 / 37$ (i.e. around $13.5 \%$ ) and all the other topics by a factor of $3 / 37$ (i.e. around $8.1 \%$ ). The sum of all weights is $100 \%$ (OECD, 2018). This algorithm allows the visitors to see in real time how the BLI rank changes with the change in the score associated to the topics. Starting from 2011, more than 100,000 users of the Better Life Index around the world have shared their views and the OECD has collected these data. The microdata can be downloaded and in 
addition to the individual well-being ratings, they show the territorial origin of the visitors, i.e. the country ${ }^{3}$. It is worth remarking that these opinions are not necessarily representative, since there is an intrinsic self-selection in people visiting this dedicated website. Although the sample is small and admittedly suffers from a sample selection bias, it nevertheless provides the unique source of information about priorities among the different dimensions of well-being included in the BLI. We have 130,710 individual preferences from all the 36 countries where the BLI is measured and 147,738 individual preferences in total (considering also the preferences from the countries not included in BLI dataset). In Table 3, the descriptive statistics for the weights are reported. Some information about the perceived trade off can be seen in the average and median ratings (second and third column in Table 3). On this point 'Civic engagement' is, globally, the lowest preferred topic describing the well-being, while 'Education', 'Health', 'Life Satisfaction', and 'Safety' have the highest average and median values.

In order to compare the topic values in (4) with the individual weights, we normalize the topic in the interval $[0,5]$ as the weights. More in details, in order to have discrete values (as the weights given by people on OECD website), we divided the distribution of Norm_Topic $k_{k}$ described in (4) into six quantiles, and we assign 0 to the first quantile, 1 to the second, 2 to the third, 3 to the fourth, 4 to the fifth, and 5 to the sixth. With this procedure, for each topic we have a rating (from 0 to 5) that reflect the policy makers' supply (to what extent policy makers are providing it). These ratings, together with the ratings provided by people, will be used in the measurement of the loss function described in the following section.

\section{The societal loss function}

The use of societal loss function stems from the original (unidimensional) spatial model presented in the Hotelling (1929)'s seminal work. Following Hotelling (1929)'s contribution,

\footnotetext{
${ }^{3}$ Our micro data have been downloaded the 15 December 2018.
} 
Downs (1957) for the first time, used a spatial model in a democratic political competition context before Davis et al. (1972) introduced the first multidimensional spatial model to study political competition over multiple policy issues. More precisely, it is worth recalling that in the model proposed by Davis et al. (1972) each policy issue correspond to a dimension in a vector space. The standard approach in political economy is to assume that agents (individuals and policy makers) have an ideal policy represented by a point in the vector space.

Hence, in line with Downs (1957) let us start with a unidimensional policy space, in which the $i$-th citizen has a policy preference $g_{\text {individual }}^{i}$ and each country $j$ implements a policy $g_{\text {country }}^{j}$, with $g_{\text {individual }}^{i}$ and $g_{\text {country }}^{j}$ real values. In this context, the $i$-th citizen has a disutility measured by the distance between the policy $g_{\text {country }}^{j}$ implemented in the country $j$, and its own policy preference $g_{\text {individual }}^{i}$ :

$$
\text { (5) } U_{i}\left(g_{\text {country }}^{j}\right)=-d\left(g_{\text {country }}^{j}, g_{\text {individual }}^{i}\right)
$$

Following the axiomatic foundation provided in Eguia (2011), in a $K$-dimensional policy space in which $g_{\text {individual }}^{i}$ and $g_{\text {country }}^{j}$ are vectors with $K$ components with the $k$-th components $g_{\text {individual, } k}^{i}$ and $g_{\text {country, } k}^{j}$ measuring the importance of $k$-th topic, the individual disutility for $i$-th citizen with respect to the implemented policy $g_{\text {country }}^{j}$ can be expressed as

(6) $U_{i}\left(g_{\text {country }}^{j}\right)=-d^{\delta}\left(g_{\text {country }}^{j}, g_{\text {individual }}^{i}\right)=\left(\sum_{k=1}^{K}\left|g_{\text {country }, k}^{j}-g_{\text {individual }, k}^{i}\right|^{\delta}\right)^{1 / \delta}$

The parameter $\delta$ represents the agent's sensitivity to policies different from her preferred mix. To this regard it is worth noticing that while for values of $\delta \geq 1$ the function $d^{\delta}\left(g_{\text {country }}^{j}, g_{\text {individual }}^{i}\right)$ in (6) is a Minkowski (1886) metric, with $\delta<1$ it is not a metric because it violates the triangle inequality (Eguia, 2011). In the extant literature (Kramer, 1977; 
Enelow, Hinich, 1981; Feddersen, 1992; Schofield, Sened, 2006; Schofield, 2007; HortalaVallve, Esteve-Volart, 2011), the preferences on the different policies have been expressed by quadratic utility (distance) function or, more generally, concave in the Euclidean distance to the ideal point of the agent (Eguia, 2011). Consistently with this practice, we adopt two different distance functions with $\delta \geq 1$. Namely, the Euclidean distance corresponding to $\delta=2$ and the taxicab distance corresponding to $\delta=1$.

In order to aggregate the individual loss function at country level, a decision must be taken about the social welfare function. On the point two extreme views have been proposed: the Bentham Utilitarianism (Bentham, 1789), and the Rawlsian approach (Rawls, 1971). According to the Benthamian approach the social welfare function is given by the sum of the individual utilities. Therefore, the social welfare function conceptually accepts a complete trade-off (or compensability) among individual utilities. In our case, for the country $j$ the Bentham societal loss function for the implemented policy $g^{j}$ is:

$$
\text { (7) } U_{j}^{B}\left(g_{\text {country }}^{j}\right)=\sum_{i} U_{i}\left(g_{\text {country }}^{j}\right)=\sum_{i}-d\left(g_{\text {country }}^{j}, g_{\text {individual }}^{i}\right)
$$

This is the approach used in Smith (2000) to compare the outcomes of different election methods. Since we have a differentiated dataset where the number of voters changes among the different countries, we propose to measure the Bentham country-level disutility as the average loss function (average loss per preference):

$$
\text { (8) } U_{j}^{B}\left(g_{\text {country }}^{j}\right)=\frac{1}{n} \sum_{i} U_{i}\left(g_{\text {country }}^{j}\right)=\frac{1}{n} \sum_{i}-d\left(g_{\text {country }}^{j} g_{\text {individual }}^{i}\right)
$$

where $n$ is the number of voters in the country $j$. 
In the Rawlsian approach instead, the social utility function is given by the minimum of the individual utilities. In our case, therefore, for the country $j$ the Rawlsian societal loss function for the implemented policy $g_{\text {country }}^{j}$ is given by:

$$
\text { (9) } U_{j}^{R}\left(g_{\text {country }}^{j}\right)=\min _{i=1, \ldots, n} U_{i}\left(g_{\text {country }}^{j}\right)=\max _{i=1, \ldots, n} d\left(g_{\text {country }}^{j}, g_{\text {individual }}^{i}\right)
$$

In other words, the Rawls country-level disutility is given by the disutility of the less happy citizen (maxi-min method).

It is worth remarking that these two types of societal loss function can be interpreted as two versions of a social disutility expressed as a power mean that is:

$$
U_{j}^{P M}\left(g_{\text {country }}^{j}\right)=\frac{1}{n}\left[\sum_{i}-d\left(g_{\text {country }}^{j}, g_{\text {individual }}^{i}\right)^{r}\right]^{1 / r}, r \in \mathbf{R} \cup\{-\infty,+\infty\}
$$

In this perspective, the Bentham societal disutility corresponds to the case $r=1$ and the Rawlsian societal disutility to the limit as $r$ approaches $-\infty$ (see e.g. Bullen 2003).

The following section presents an analysis of the societal loss of well-being according to both the Benthamian and the Rawlsian social disutility.

An alternative new way to measure the well-being on BLI at country-level is treating all the individuals as a unique global community and evaluating the policy makers' offer in terms of mix of well-being, on the basis of the global societal favourite country. Denoting by $g_{\text {country }}^{j}$ the mix of well-being in the country $j(j=1, \ldots, m)$, then for the individual $i$, the favourite country in the set is the country $j^{*}(i)$ that minimizes her loss function, that is:

(10) $j^{*}(i)=\underset{j=1, \ldots, m}{\operatorname{argmax}} U_{i}\left(g_{\text {country }}^{j}\right)=\underset{j=1, \ldots, m}{\operatorname{argmin}} d^{\delta}\left(g_{\text {country }}^{j} g_{\text {individual }}^{i}\right)=\underset{j=1, \ldots, m}{\operatorname{argmin}}\left(\sum_{k=1}^{K}\left|g_{\text {country,k }}^{j}-g_{\text {individual, },}^{i}\right|^{\delta}\right)^{1 / \delta}$ 
Analogously, we can find the least favourite country $j_{*}(i)$ for the individual $i$, as the country that maximizes her loss function, that is:

$$
j_{*}(i)=\underset{j=1, \ldots, m}{\operatorname{argmin}} U_{i}\left(g_{\text {country }}^{j}\right)=\underset{j=1, \ldots, m}{\operatorname{argmax}} d^{\delta}\left(g_{\text {country }}^{j}, g_{\text {individual }}^{i}\right)=\underset{j=1, \ldots, m}{\operatorname{argmax}}\left(\sum_{k=1}^{K}\left|g_{\text {country }, k}^{j}-g_{\text {individual }, k}^{i}\right|^{\delta}\right)^{1 / \delta}
$$

By adopting such a global lens, we can evaluate the countries on the basis of the share of people that ranks the country first and last.

\section{Results}

As explained in the Section 3, in order to estimate the aggregate societal loss of well-being in the OECD countries we express the individual disutility in two different ways: (i) the Euclidean distance, and (ii) the taxicab norm. Moreover, we express the societal loss of well-being with two different aggregations of individual loss functions: the Benthamian societal welfare function (eq. 8), and the Rawlsian social welfare function (eq. 9). As a result of the combination between distance function and aggregate social loss we obtain four different values of social loss for each country. These results are reported in the next Section; then we contrast the above loss values with three different indicators of 'voice' taken from the World Happiness Indicator (Helliwell et al. 2016), and from the Worldwide Governance Indicators (Kaufmann et al. 2011). Furthermore, we compare our loss function with different composite indices of well-being from BLI; and finally we compare the country level BLI by minimizing the individual loss functions.

\section{The societal loss of Better Life Index}

As mentioned, in this section four societal loss functions are presented: 1. the individual taxicab aggregated with the Benthamian approach, 2. the individual taxicab aggregated with the Rawlsian approach, 3. the individual Euclidean aggregated with the Benthamian approach, and 4. the individual Euclidean aggregated with the Rawlsian approach. Table 4 reports the country-level societal loss due to mismatching between the individually optimal mix of well- 
being and the mix of well-being provided by the policy makers at country level. As long as the form of the individual loss function is concerned, we do not observe relevant differences among the results generated using the different assumptions. Indeed, the rank correlations between the taxicab and Euclidean function is $\mathbf{0 . 6 7}$ with the Benthamian aggregation, and it is $\mathbf{0 . 9 2}$ with the Rawlsian aggregation (see tab A1 in the Appendices). Therefore, different sensitivities in observing a policy outcome different from the individually preferred one are not relevant to this respect. However, the aggregation technique - and the underlying system of values - are more relevant to the final ranks, indeed the rank correlation between the Benthamian and Rawlsian aggregation is 0.55 with taxicab norm and 0.74 with the Euclidean function (see tab A1 in the Appendices). ${ }^{4}$ As shown in Table 4, the highest societal losses depend on both aggregation technique and functional form, and are registered in Turkey (taxicab, Bentham), Brazil (taxicab/Euclidean Rawls), Russia (Euclidean Bentham). Likewise, both aggregation technique and functional form play a relevant role in determining the lowest loss function. On the bottom side of the ranking (i.e. better performance due to lower loss values) are placed United Kingdom (taxicab, Bentham), Finland (taxicab Rawls), Norway (Euclidean Rawls) and New Zealand (Euclidean Bentham).

An extensive discussion of the loss and of the related ranking achieved by each country goes beyond the scope of the current analysis. Nonetheless, in what follows we conjecture that the 'voice' aspect of the democratic processes ongoing in the considered countries can positively influence the way the final observed outcome in terms of mix of well-being indicators reflects citizens' preferences on the same matter. Next section addresses this issue.

\footnotetext{
${ }^{4}$ Part of these results may be due to the fact that $\delta$-values in taxicab and Euclidean (1 and 2) are close to each other. As far as the societal loss function is concerned, the higher impact may be instead due to the higher differentiated r-values because, as previously noted, Rawlsian societal disutility corresponds to r-parameter approaching $-\infty$ and Bentham societal disutility corresponds to rparameter equal to one.
} 


\section{Comparisons among different indexes of 'voice'}

In the economic theory the distance between the individual optimal mix of well-being and the mix provided by the policy makers results from two main forces: the voice and the mobility (Tiebout, 1956; Downs, 1957; Hirschman, 1970). In other words, people that are unhappy with the mix of well-being provided by policy makers can change their situation either by voting for another policy maker, by a revolution, or by changing country (Hirschman, 1970). Therefore, the differences in the mismatching between individual and country-level mix can be explained by the balance of the operating of these forces. In this section we explore to what extent the mismatching between the individual optimal mix and the policy maker mix can be explained in terms lack of citizen involvement in public decisions.

To this end we show the relation between our societal loss function and some proxies of quality of democracy provided by the international institutions. We choose three different indicators to measure the quality of the democracy: the index of 'Freedom to make life choices', and the index of 'Democratic Quality', both provided by World Happiness Index (Helliwell et al. 2016); and the 'Voice Index' provided by the Worldwide Governance Indicators (Kaufmann et a. 2011). Table A1 in the Appendices shows that there is significant negative correlation between our estimated loss functions and any voice index taken into account. Indeed, using respectively taxicab Bentham, Euclidean Bentham, taxicab Rawls, and Euclidean Rawls, the correlations our loss function are:

- $-0.55,-0.65,-0.55,-0.66$ with the index of 'Freedom to make life choices',

- $-0.45,-0.69,-0.73,-0.78$ with the index of 'Democratic Quality',

- $-0.47,-0.60,-0.42,-0.55$ with the 'World Happiness Index',

- $-0.52,-0.68,-0.61,-0.70$ with the 'Voice Index'. 
These results reveal that there is a strong relation between our societal loss function and the lack in the quality of the democracy. In particular, higher negative associations have been found with 'Democratic Quality' and 'Voice Index', and lower association have been found with 'Freedom to make life choices' and 'World Happiness Index'. This proves that our approach can be considered as a valuable support to understand social phenomena and the OECD survey is quite representative. In particular, Table A1 shows that stronger associations are those referring more to indices more targeted on the decision making process (Democratic quality and Voice in particular).

Since the correlation between the taxicab and the Euclidean preferences is high and significant (see Table A1 in the Appendices), for convenience of presentation we are going to use only the taxicab preferences in this stage of the analysis.

We propose a quadrant analysis in order to explore similarities among countries with similar level of loss function and voice indices. Figure 1 shows the relation between the estimated loss functions and the index of 'Freedom to make life choices' (Helliwell et al., 2016). Figures 1, 2, 3, and 4 report two lines representing the respective median values. Since the correlation between the two variables is negative (Tab. A1 in the Appendices), the majority of values lay on the second and the fourth quadrant. In other words, countries with more (less) societal loss function have also less (more) freedom to make life choices. There are some interesting exceptions in Figure 1: Israel has less freedom to make life choice, and it has also lower values of societal loss function. On the other side, USA and Poland have high freedom to make life choice and quite interestingly also high societal loss function. These evidences may signal that in these countries other factors (not included in the BLI) play a relevant rule in the individuals' 'freedom to make life choice'. 
Figure 2 shows the relation between the estimated loss functions and the index of 'Democratic Quality' (Helliwell et al. 2016). Alike the previous case, due to the negative correlations between these variables (Tab. A1 in the Appendices), the values tend to concentrate into the second and the fourth quadrant. It is worth noticing the presence of some outliers such as, again, Israel, that have low democratic quality and also low societal loss of well-being, and Canada, showing high democratic quality and high Rawls societal loss of well-being.

Figure 3 shows the relation between the estimated loss functions and the 'Voice Index' (Kaufmann et al. 2011). In terms of robustness, it is worth noticing that although the "Voice Index' is estimated by another institution, we observe that the big picture is quite close to that of Figure 1 and Figure 2. We observe the majority of the values on the second and fourth quadrant and almost the same interesting outliers: Israel, Canada, and USA.

\section{The relation between loss function and composite indices of well-being from BLI}

In order to study the relation between the amount of well-being and the aforementioned mismatching phenomenon, we compute two different composite indices of well-being starting from the BLI. The first is the simple average of the indicators, as the original BLI proposed by OECD (2011) and the second is an aggregation with the 'Benefit of Doubt' as proposed in Mizobuchi (2014). A preliminary analysis on the relation between the amount of well-being (estimated by BOD and average aggregation) and the societal loss function is reported in the correlation matrix A1 in the Appendices. According to Table A1 there is a significant negative relation between the two measures, regardless of the aggregation technique. We interpret this finding as a tentative evidence that countries with higher levels of mismatching are also countries with lower levels of the Better Life Index. To develop further this conjecture, we plotted our data as reported in Figure 4 that shows the relation between the societal loss and the average BLI. Due to the negative relation between well-being and loss function, the second and the fourth quadrant are also in this case the most crowded ones. The most interesting cases 
are USA and Canada with both a high average well-being and a high societal loss function. In this case, therefore, we have a high level of well-being that is not matching with people preferences as expressed in the BLI. On the other side, we observe that in Portugal, despite the lower amount of well-being, the Rawlsian loss function is low.

The major points reported in Figure 4 are confirmed by changing the aggregation technique of well-being. More in detail, as far as the relation between the loss functions and the BOD BLI is concerned, the more relevant outliers are USA, Poland, and Canada with high BLI and high societal loss. This means that the multidimensional well-being in these countries is unbalanced on topics in which people voting on OECD website care less. In particular, the USA performs well in Income and Wealth (topic in which people care less), while performance is poorly in Health (topic in which people are more interested). On the other side, Portugal has both a low BOD BLI and a low Rawlsian loss of BLI. This signals that Portugal has lower BLI, mainly due to poor resources (see Patrizii et al., 2017), but with the proportions among the different dimensions of BLI are in line with the people's relative appreciation.

\section{The country-level loss function}

This section introduces a new way to measure the well-being on BLI at country-level. One that (i) treats all the individuals as a unique global community and (ii) evaluate the policy makers' offer in terms of mix of well-being, on the basis of the global societal favourite country. The underlying idea is that each individual has its own favourite country according to the distance between its optimal point and the country-level mix. Formally, for each individual the favourite country is the country that minimizes her loss function (10), and the least favourite country is the country that maximizes her loss function (11). By adopting such a global lens, we evaluate the countries on the basis of the share of people that ranks the country first and last.

Table 5 shows the share of $\mathbf{1 4 8 , 7 3 8}$ individuals belonging to the sample collected from the OECD website that ranks each country first and last with taxicab and Euclidean loss function. 
On the top side of the rank (second and third column in Table 5) Norway is the favoured Country according to the majority of individuals. This result is substantially confirmed with both taxicab and Euclidean loss function. Indeed, the $13 \%$ of individuals rank Norway first assuming taxicab loss function, and the $19 \%$ of individuals rank Norway first assuming Euclidean loss function. Brazil and Slovenia register a relatively good ranking placing them among the first three countries assuming taxicab loss function. Similarly, Austria and Slovenia are placed among the first three countries according to the Euclidean loss function.

On the bottom side of the ranking (fourth and fifth column in Table 5) Turkey is the least favorite country by the $35 \%$ and the $44 \%$ of individuals assuming taxicab and Euclidean loss function, respectively. In the last third positions, there are also Mexico and Brazil, both with the taxicab and Euclidean loss function.

\section{Conclusions}

This paper addressed the issue of whether and to what extent real people's preferences among different dimensions of a multidimensional measure of well-being match with the wellbeing mix effectively registered in the OECD countries as captured by the Better Life Index framework. The OECD BLI is particularly suitable for this kind of analysis because it is one of the largest dataset collecting well-being data at country level. Moreover, OECD provides a survey of the user weightings related to 11 different topics. By using these data, we interpret the country-level citizens' individual weightings as the optimal subjective mix of well-being, and we interpret the country-level values of the topics as the mix of well-being provided by policy makers. According to these assumptions, we assess the societal loss of well-being at country-level by estimating the distance between these mixes for each country included in the OECD survey. 
To the best of our knowledge, for the first time, a multidimensional spatial model of preferences is used in the well-being context. In our model, the OECD countries are objects of preferences. These preferences are expressed as points in the Euclidean K-dimensional space in which each dimension is a specific aspect of well-being. Each individual/voter is characterized by her ideal point in the aforementioned space. Then, for each individual, the distance between its optimal mix of well-being and the mix provided by policy makers can be interpreted as individual loss in well-being. Therefore, the countries are judged as good as they are close to the voters' ideal point.

The main results based on the novel methodology are that the highest societal losses are registered in Turkey, Mexico, and Brazil. While the lowest societal losses are in Norway and in Finland. By comparing our estimated societal losses and some proxies of 'voice' provided by different source of data (Helliwell et al. 2016, Kaufmann et al. 2011), it emerges that countries with lower levels democracy are also countries with higher levels of societal loss of well-being. Therefore, the detected mismatching between will of the people and policy makers' activity may be due to lack of citizens' involvement in the decisions making process. Moreover, by comparing the societal loss function and the BLI it emerges that countries with more mismatching are also countries with worse Better Life Index.

This first study has shown that multidimensional spatial framework could be a promising framework for evaluating multidimensional well-being. As further research, it would be interesting to explore the effect of different assumptions on the distance functions as the $\delta$ parameter values. To what extent these results are affected by the admitted selection bias affecting the data is unknown. Nonetheless, we argue that this analysis could play a crucial role in stimulating research involving sampling procedure within OECD Better Life Index. 
Policy makers dealing with collective choices need tools to manage the multidimensionality of phenomena and the heterogeneity of individual preferences. The mismatching between will of the people and policy makers' activity allows to reflect to what extent people's preferences reflects policy outcome, and higher mismatching may signal the lack of citizens' involvement in the decisions making process. This mismatching can determine the disconnection between citizens and policy maker, and even between citizens and politics. In the long run these phenomena are breeding ground for demagogy and other undesirable outcomes. The new tools proposed in this paper, can certainly be a valid support for better-informed decisions and policy formulations. Although at the moment the present study is focused on BLI that is mainly measured in OECD countries, such studies for the developing world can be implemented by means of Big data (Laney, 2001). Indeed, recent studies have shown that Big data can offer many opportunities to evaluate multidimensional well-being and people's priorities (see di Bella et al. 2017; Resce, Maynard, 2018).

The methodology proposed here is applicable to all problems in which a group of individuals expresses their weights individually on a set of dimensions within a pre-established range. Hence, theoretically the multidimensional spatial model, in turn, can be applied to all the multidimensional measures of well-being. Nonetheless, it is worth noticing that the framework does not account for other multidimensional measures represented by people's votes. It is therefore to be hoped that the OECD approach to allow each visitor to calculate its own Better Life Index will be generalized in the future for a more participatory approach for the construction of composite indices of public interest. 


\section{References}

Alesina, A. F., \& Giuliano, P. (2009). Preferences for redistribution (No. w14825). National Bureau of Economic Research.

Bentham, J. (1789). An Introduction to the Principles of Morals and Legislation (Payne, London). Reprinted in 1970 in: J.M. Burns and H.L.A. Hart, eds. (Athlone Press, London).

di Bella, E., Leporatti, L., \& Maggino, F. (2017). Big data and social indicators: Actual trends and new perspectives. Social Indicators Research, 1-10.

Bleys, B. (2012). Beyond GDP: Classifying Alternative Measures for Progress, Social Indicators Research, 109, 355-376.

Bogomolnaia, A., \& Laslier, J. F. (2007). Euclidean preferences. Journal of Mathematical Economics, 43(2), 87-98.

Bullen, P. S. (2003). The Power Means. Ch. 3 in Handbook of Means and Their Inequalities. Kluwer, Dordrecht, Netherlands, pp. 175-265.

Costanza, R., Daly, L., Fioramonti, L., Giovannini, E., Kubiszewski, I., Mortensen, L. F., ... \& Wilkinson, R. (2016). Modelling and measuring sustainable wellbeing in connection with the UN Sustainable Development Goals. Ecological Economics, 130, 350-355.

Costanza, R., Kubiszewski, I., Giovannini, E., Lovins, H., McGlade, J., Pickett, K. E., ... \& Wilkinson, R. (2014). Development. Nature, 505(7483), 283-285.

Charron, N., Dijkstra, L., \& Lapuente, V. (2014). Regional governance matters: Quality of government within European Union member states. Regional Studies, 48(1), 68-90.

Coyle D. (2014) GDP: A brief but affectionate history, Princeton University Press, Princeton. 
Davis, O. A., DeGroot, M. H., \& Hinich, M. J. (1972). Social preference orderings and majority rule. Econometrica: Journal of the Econometric Society, 147-157.

De Beukelaer C. (2014) Gross Domestic Problem: The Politics Behind the World's Most Powerful Number, Journal of Human Development and Capabilities 15.2-3, 290-291.

Decancq, K., \& Schokkaert, E. (2013). Beyond GDP: Measuring social progress in Europe.

Downs, A. (1957). An economic theory of political action in a democracy. Journal of Political Economy, 65(2), 135-150.

Durand, M. (2015). The OECD Better Life Initiative: How's Life? and the Measurement of Well-Being. Review of Income and Wealth, 61(1), 4-17.

Eguia, J. X. (2011). Foundations of spatial preferences. Journal of Mathematical Economics, 47(2), 200-205.

Enelow, J., \& Hinich, M. J. (1981). A new approach to voter uncertainty in the Downsian spatial model. American journal of political science, 483-493.

Feddersen, T. J. (1992). A voting model implying Duverger's law and positive turnout. American journal of political science, 938-962.

Fioramonti L. (2013) Gross domestic problem: The politics behind the world's most powerful number, Zed Books.

Fleurbaey M. (2009) Beyond GDP: The quest for a measure of social welfare, Journal of Economic Literature, 1029-1075

Frey, B. S., \& Stutzer, A. (2010). Happiness and public choice. Public Choice, 144(3-4), 557573. 
Helliwell J.F. (2003) How's life? Combining individual and national variables to explain subjective well-being, Economic Modelling, 20(2), 331-360.

Helliwell J.F., Barrington-Leigh C. P. (2010) Viewpoint: Measuring and understanding subjective well-being, Canadian Journal of Economics/Revue canadienne d'économique, 43(3), 729-753.

Helliwell, J. F., Huang, H., \& Wang, S. (2016). The distribution of world happiness. WORLD HAPPINESS, 8.

Hervé, M. (2015). Diverse basic statistical and graphical functions, R package version 0.9-52. http://CRAN.R-project.org/package=RVAideMemoire.

Hirschman A.O. (1970) Exit, voice, and loyalty: Responses to decline in firms, organizations, and states (Vol. 25). Harvard university press.

Hortala-Vallve, R., \& Esteve-Volart, B. (2011). Voter turnout and electoral competition in a multidimensional policy space. European journal of political economy, 27(2), 376-384.

Hotelling, H. (1929). Stability in competition. Economic Journal, 39 (153), 41-57.

Kaldor, N. (1981) "The role of increasing returns, technical progress and cumulative causation in the theory of international trade and economic growth," Économie Appliquée, 34, 593-617. Reprinted in Further Essays on Economic Theory and Policy, New York, Holmes and Meier, 1989.

Karabell Z. (2014) The leading indicators: a short history of the numbers that rule our world, Simon and Schuster.

Kaufmann, D., Kraay, A., \& Mastruzzi, M. (2011). The worldwide governance indicators: methodology and analytical issues. Hague Journal on the Rule of Law, 3(2), 220-246.

Kramer, G. H. (1977). A dynamical model of political equilibrium. Journal of Economic Theory, 16(2), 310-334. 
Laney, D. (2001). 3D data management: Controlling data volume, velocity and variety. META Group Research Note, 6, 70.

Minkowski, H. (1886). Geometrie der Zahlen. Teubner Verlag, Leipzig.

Mizobuchi, H. (2014). Measuring world better life frontier: a composite indicator for OECD better life index. Social Indicators Research, 118(3), 987-1007.

Myrdal, G. (1957) Economic Theory and Underdeveloped Regions, London, Duckworth. Schumpeter J. (1954) History of Economic Analysis, London, Allen \& Unwin.

OECD. (2011). Compendium of OECD well-being indicators. Paris: OECD Publishing.

OECD (2018), How's life?: http://www.oecdbetterlifeindex.org/about/better-lifeinitiative/

Patrizii, V., Pettini, A., \& Resce, G. (2017). The Cost of Well-Being. Social Indicators Research, 133(3), 985-1010.

Persson, T., \& Tabellini, G. E. (2002). Political economics: explaining economic policy. MIT press.

Porter, M. E. et al. (2000). The global competitiveness report 2000. Oxford University Press, Oxford.

Rawls, J. (1971). A Theory of Justice, Harvard University Press, Cambridge, Mass.

Resce, G., \& Maynard, D. (2018). What matters most to people around the world? Retrieving Better Life Index priorities on Twitter. Technological Forecasting and Social Change.

Rothstein, B. (2011). The quality of government: Corruption, social trust, and inequality in international perspective. University of Chicago Press.

Schofield, N. (2007). The mean voter theorem: necessary and sufficient conditions for convergent equilibrium. The Review of Economic Studies, 74(3), 965-980. 
Schofield, N., \& Sened, I. (2006). Multiparty democracy: elections and legislative politics. Cambridge University Press.

Sen, A. (1985). Commodities and Capabilities, North-Holland Publishing, Amsterdam.

Smith, W. D. (2000). Range voting. The paper can be downloaded from the author's homepage at http://www. math. temple. edu/ wds/homepage/works. html.

Stiglitz, J. E., Sen, A., \& Fitoussi, J. P. (2010). Report by the commission on the measurement of economic performance and social progress. Paris: Commission on the Measurement of Economic Performance and Social Progress.

Tiebout, C. M. (1956). A pure theory of local expenditures. Journal of political economy, 64(5), 416-424.

UNDP (1996) Human Development Report. United Nation Development Programme, Nairobi, Kenia.

UNDP. (1990). UNDP Human Development Report 1990 Oxford University Press, New York

Veblen, T.B. (1919) The Place of Science in Modern Civilisation and Other Essays, New York, Huebsch.

Young, A. (1928) 'Increasing returns and economic progress,' Economic Journal, 38, 527-42. 
Table 1: Topics and related variables of the BLI

\begin{tabular}{|c|c|}
\hline Topics & Related variables \\
\hline \multirow{3}{*}{ Housing } & Dwellings without basic facilities (N) \\
\hline & Housing expenditure $(\mathrm{N})$ \\
\hline & Rooms per person $(\mathrm{P})$ \\
\hline Income & $\begin{array}{l}\text { Household net adjusted disposable income }(\mathrm{P}) \\
\text { Household net financial wealth }(\mathrm{P})\end{array}$ \\
\hline Jobs & $\begin{array}{l}\text { Employment rate }(\mathrm{P}) \\
\text { Job security }(\mathrm{N}) \\
\text { Long-term unemployment rate }(\mathrm{N}) \\
\text { Personal earnings }(\mathrm{P})\end{array}$ \\
\hline Community & Quality of support network $(\mathrm{P})$ \\
\hline & Educational attainment $(\mathrm{P})$ \\
\hline Education & Student skills $(\mathrm{P})$ \\
\hline & Years in education $(\mathrm{P})$ \\
\hline Environment & $\begin{array}{l}\text { Air pollution }(\mathrm{N}) \\
\text { Water quality }(\mathrm{P})\end{array}$ \\
\hline Civic engagement & $\begin{array}{l}\text { Consultation on rule-making }(\mathrm{P}) \\
\text { Voter turnout }(\mathrm{P})\end{array}$ \\
\hline Health & $\begin{array}{l}\text { Life expectancy }(\mathrm{P}) \\
\text { Self-reported health }(\mathrm{P})\end{array}$ \\
\hline Life Satisfaction & Life satisfaction $(\mathrm{P})$ \\
\hline Safety & $\begin{array}{l}\text { Assault rate }(\mathrm{N}) \\
\text { Homicide rate }(\mathrm{N})\end{array}$ \\
\hline Work-Life Balance & $\begin{array}{l}\text { Employees working very long hours }(\mathrm{N}) \\
\text { Time devoted to leisure and personal care }(\mathrm{P})\end{array}$ \\
\hline
\end{tabular}

Table 2. Summary of the topic values

\begin{tabular}{lrrrr}
\hline Topic & Average & StDev & Min & Max \\
\hline Housing & 5.51 & 1.48 & 2.06 & 8.21 \\
Income & 3.40 & 2.22 & 0.13 & 10 \\
Jobs & 6.54 & 1.85 & 1.49 & 9.53 \\
Community & 7.35 & 2.12 & 0 & 10 \\
Education & 6.40 & 1.93 & 0.52 & 9.13 \\
Environment & 6.78 & 1.99 & 2.07 & 9.62 \\
Civic engagement & 5.07 & 1.93 & 0 & 9.47 \\
Health & 6.83 & 1.95 & 0.58 & 9.35 \\
Life Satisfaction & 6.60 & 2.92 & 0 & 10 \\
Safety & 8.30 & 1.93 & 0.42 & 9.96 \\
Work-Life Balance & 6.66 & 1.88 & 0 & 9.77 \\
\hline Source: Authors
\end{tabular}

Source: Authors' analysis on OECD data 
Table 3: Summary of the Weights for each Topic

\begin{tabular}{|c|c|c|c|c|c|c|c|}
\hline & Average & Median & & & Min & & \\
\hline Housing & 3.21 & & 3 & 1.49 & & $\mathbf{0}$ & 5 \\
\hline Income & 3.07 & & 3 & 1.44 & & $\mathbf{0}$ & 5 \\
\hline Jobs & 3.15 & & 3 & 1.45 & & $\mathbf{0}$ & 5 \\
\hline Community & 2.86 & & 3 & 1.47 & & $\mathbf{0}$ & 5 \\
\hline Education & 3.51 & & 4 & 1.52 & & $\mathbf{0}$ & 5 \\
\hline Environment & 3.21 & & 3 & 1.53 & & $\mathbf{0}$ & 5 \\
\hline Civic engagement & 2.37 & & 2 & 1.42 & & $\mathbf{0}$ & 5 \\
\hline Health & 3.70 & & 4 & 1.49 & & $\mathbf{0}$ & 5 \\
\hline Life Satisfaction & 3.63 & & 4 & 1.53 & & $\mathbf{0}$ & 5 \\
\hline Safety & 3.29 & & 4 & 1.53 & & $\mathbf{0}$ & 5 \\
\hline Work-Life Balance & 3.30 & & 3 & 1.52 & & $\mathbf{0}$ & 5 \\
\hline
\end{tabular}

Data extracted on 15 Dec 2018 from OECD.Stat; Number of individuals per country:

Australia 14341, Austria 2901, Belgium 2027, Brazil 2583, Canada 7089, Chile 1442, Czech

Republic 728, Denmark 938, Estonia 223, Finland 823, France 15189, Germany 12827, Greece

943, Hungary 1198, Iceland 168, Ireland 704, Israel 919, Italy 4807, Japan 1533, Korea 995, Luxembourg 279, Mexico 8536, Netherlands 1321, New Zealand 956, Norway 1730, Poland 1489, Portugal 1840, Russia 2743, Slovak Republic 333, Slovenia 220, Spain 4906, Sweden 1262, Switzerland 2768, Turkey 2345, United Kingdom 5574, United States 22030. 
Table 4. Societal Loss of BLI

\begin{tabular}{|c|c|c|c|c|}
\hline \multirow{2}{*}{ country } & \multicolumn{2}{|c|}{ taxicab norm } & \multicolumn{2}{|c|}{ Euclidean } \\
\hline & Bentham & Rawls & Bentham & Rawls \\
\hline Australia & 20.65 & 36 & 7.44 & 11.40 \\
\hline Austria & 18.32 & 33 & 6.48 & 10.44 \\
\hline Belgium & 20.03 & 36 & 7.26 & 11.49 \\
\hline Brazil & 24.90 & 51 & 9.18 & 15.46 \\
\hline Canada & 17.28 & 38 & 6.46 & 11.83 \\
\hline Chile & 22.48 & 39 & 8.54 & 13.23 \\
\hline Czech Republic & 21.75 & 34 & 7.90 & 11.75 \\
\hline Denmark & 18.57 & 34 & 6.83 & 10.86 \\
\hline Estonia & 23.71 & 41 & 8.72 & 13.53 \\
\hline Finland & 17.32 & 32 & 6.43 & 10.49 \\
\hline France & 17.51 & 36 & 6.56 & 11.49 \\
\hline Germany & 17.35 & 34 & 6.45 & 10.95 \\
\hline Greece & 21.93 & 35 & 8.21 & 12.37 \\
\hline Hungary & 23.12 & 36 & 8.53 & 12.29 \\
\hline Iceland & 19.12 & 35 & 6.83 & 11.18 \\
\hline Ireland & 21.01 & 35 & 7.82 & 11.79 \\
\hline Israel & 19.91 & 36 & 7.41 & 12.00 \\
\hline Italy & 21.95 & 39 & 8.15 & 12.21 \\
\hline Japan & 20.68 & 35 & 7.71 & 11.62 \\
\hline Korea & 23.99 & 36 & 8.75 & 12.25 \\
\hline Luxembourg & 21.76 & 33 & 7.78 & 10.82 \\
\hline Mexico & 26.79 & 41 & 9.73 & 13.56 \\
\hline Netherlands & 19.50 & 35 & 7.32 & 11.62 \\
\hline New Zealand & 18.73 & 32 & 6.79 & 10.39 \\
\hline Norway & 16.88 & 33 & 6.25 & 10.44 \\
\hline Poland & 25.86 & 41 & 9.26 & 13.15 \\
\hline Portugal & 21.60 & 38 & 8.06 & 12.49 \\
\hline Russia & 9.02 & 45 & 25.22 & 14.39 \\
\hline Slovak Republic & 23.07 & 34 & 8.45 & 11.58 \\
\hline Slovenia & 17.01 & 34 & 6.40 & 10.86 \\
\hline Spain & 21.61 & 40 & 8.04 & 13.11 \\
\hline Sweden & 20.65 & 33 & 7.46 & 10.77 \\
\hline Switzerland & 20.92 & 35 & 7.57 & 11.62 \\
\hline Turkey & 27.53 & 46 & 9.98 & 14.83 \\
\hline United Kingdom & 6.69 & 34 & 18.72 & 10.68 \\
\hline United States & 23.41 & 43 & 8.31 & 13.38 \\
\hline
\end{tabular}

Source: Authors' analysis on OECD data. 
Table 5 Share of individuals ranking the country first and last

\begin{tabular}{|c|c|c|c|c|c|c|}
\hline \multirow{2}{*}{ Country } & \multicolumn{2}{|c|}{ Favorite } & \multicolumn{2}{|c|}{ Least Favorite } & \multicolumn{2}{|c|}{ Rank position } \\
\hline & taxicab & Euclidean & taxicab & Euclidean & Average BLI & BOD \\
\hline Australia & $0 \%$ & $0 \%$ & 0\% & $0 \%$ & 1 & 1 \\
\hline Austria & $3 \%$ & $12 \%$ & $0 \%$ & $0 \%$ & 17 & 24 \\
\hline Belgium & $0 \%$ & 0\% & $0 \%$ & $0 \%$ & 14 & 1 \\
\hline Brazil & $6 \%$ & $0 \%$ & $16 \%$ & $14 \%$ & 31 & 33 \\
\hline Canada & $5 \%$ & $9 \%$ & 0\% & 0\% & 6 & 1 \\
\hline Chile & $2 \%$ & $1 \%$ & $1 \%$ & $1 \%$ & 34 & 35 \\
\hline Czech Republic & $1 \%$ & $1 \%$ & $1 \%$ & $0 \%$ & 22 & 21 \\
\hline Denmark & $2 \%$ & $4 \%$ & $0 \%$ & $0 \%$ & 5 & 1 \\
\hline Estonia & $0 \%$ & $0 \%$ & $2 \%$ & $1 \%$ & 28 & 30 \\
\hline Finland & $6 \%$ & $8 \%$ & $0 \%$ & 0\% & 10 & 1 \\
\hline France & $3 \%$ & $6 \%$ & 0\% & $0 \%$ & 18 & 28 \\
\hline Germany & $3 \%$ & $5 \%$ & $0 \%$ & $0 \%$ & 12 & 1 \\
\hline Greece & $1 \%$ & $0 \%$ & $1 \%$ & $2 \%$ & 33 & 27 \\
\hline Hungary & $0 \%$ & $0 \%$ & $3 \%$ & $2 \%$ & 29 & 25 \\
\hline Iceland & $2 \%$ & $1 \%$ & $1 \%$ & 0\% & 9 & 1 \\
\hline Ireland & $1 \%$ & $2 \%$ & $0 \%$ & $0 \%$ & 13 & 1 \\
\hline Israel & $1 \%$ & $2 \%$ & $0 \%$ & $0 \%$ & 23 & 22 \\
\hline Italy & $0 \%$ & $0 \%$ & 0\% & $0 \%$ & 24 & 29 \\
\hline Japan & $1 \%$ & $0 \%$ & $1 \%$ & 0\% & 20 & 1 \\
\hline Korea & $0 \%$ & $0 \%$ & $5 \%$ & $4 \%$ & 27 & 20 \\
\hline Luxembourg & $0 \%$ & $0 \%$ & $1 \%$ & 0\% & 15 & 1 \\
\hline Mexico & $0 \%$ & $0 \%$ & $19 \%$ & $21 \%$ & 36 & 36 \\
\hline Netherlands & $2 \%$ & $2 \%$ & $0 \%$ & $0 \%$ & 11 & 1 \\
\hline New Zealand & $2 \%$ & $3 \%$ & $0 \%$ & $0 \%$ & 8 & 1 \\
\hline Norway & $13 \%$ & $19 \%$ & $\mathbf{0 \%}$ & $0 \%$ & 3 & 1 \\
\hline Poland & 0\% & 0\% & $12 \%$ & $7 \%$ & 25 & 1 \\
\hline Portugal & $0 \%$ & $0 \%$ & $1 \%$ & $0 \%$ & 30 & 31 \\
\hline Russia & $1 \%$ & $0 \%$ & $8 \%$ & $5 \%$ & 32 & 34 \\
\hline Slovak Republic & $0 \%$ & $\mathbf{0 \%}$ & $2 \%$ & $2 \%$ & 26 & 23 \\
\hline Slovenia & $8 \%$ & $11 \%$ & 0\% & 0\% & 21 & 26 \\
\hline Spain & $0 \%$ & $0 \%$ & $1 \%$ & 0\% & 19 & 1 \\
\hline Sweden & $1 \%$ & 0\% & $0 \%$ & $0 \%$ & 2 & 1 \\
\hline Switzerland & $0 \%$ & $0 \%$ & $0 \%$ & $\mathbf{0 \%}$ & 4 & 1 \\
\hline Turkey & $0 \%$ & $0 \%$ & $35 \%$ & $43 \%$ & 35 & 32 \\
\hline United Kingdom & $1 \%$ & $2 \%$ & 0\% & $\mathbf{0 \%}$ & 16 & 1 \\
\hline United States & $3 \%$ & $2 \%$ & $12 \%$ & $2 \%$ & 7 & 1 \\
\hline
\end{tabular}

Source: Authors' analysis on OECD data. 
Table A1, Rank Correlation Matrix with confidence intervals (95\% bootstrap upper and lower bounds)

\begin{tabular}{|c|c|c|c|c|c|c|c|c|c|c|}
\hline & $\mathbf{A}$ & B & $\mathrm{C}$ & D & $\mathbf{E}$ & $\mathbf{F}$ & $\mathbf{G}$ & H & I & $\mathbf{L}$ \\
\hline A & 1.000 & & & & & & & & & \\
\hline LB & 0.270 & & & & & & & & & \\
\hline B & 0.676 & 1.000 & & & & & & & & \\
\hline UB & 0.989 & & & & & & & & & \\
\hline LB & 0.189 & & & & & & & & & \\
\hline C & 0.552 & 0.639 & 1.000 & & & & & & & \\
\hline UB & 0.803 & & & & & & & & & \\
\hline LB & 0.362 & 0.356 & 0.801 & & & & & & & \\
\hline D & 0.691 & 0.743 & 0.919 & 1.000 & & & & & & \\
\hline UB & 0.896 & 0.828 & 0.970 & & & & & & & \\
\hline LB & -0.741 & 0.426 & -0.734 & -0.784 & & & & & & \\
\hline $\mathbf{E}$ & -0.555 & -0.653 & -0.548 & -0.661 & 1.000 & & & & & \\
\hline UB & -0.284 & 0.906 & -0.298 & -0.473 & & & & & & \\
\hline LB & -0.743 & -0.771 & -0.858 & -0.886 & 0.720 & & & & & \\
\hline $\mathbf{F}$ & -0.448 & -0.689 & -0.734 & -0.781 & 0.859 & 1.000 & & & & \\
\hline UB & -0.120 & -0.451 & -0.502 & -0.594 & 0.913 & & & & & \\
\hline LB & -0.714 & -0.840 & -0.643 & -0.726 & 0.529 & 0.432 & & & & \\
\hline G & -0.475 & -0.601 & -0.424 & -0.546 & 0.756 & 0.675 & 1.000 & & & \\
\hline UB & -0.167 & -0.447 & -0.122 & -0.309 & 0.886 & 0.824 & & & & \\
\hline LB & -0.776 & -0.792 & -0.805 & -0.853 & 0.681 & 0.680 & 0.405 & & & \\
\hline $\mathbf{H}$ & -0.526 & -0.680 & -0.608 & -0.703 & 0.832 & 0.859 & 0.675 & 1.000 & & \\
\hline UB & -0.186 & -0.365 & -0.320 & -0.473 & 0.890 & 0.932 & 0.827 & & & \\
\hline LB & -0.689 & $-\mathbf{0 . 8 3 7}$ & -0.755 & -0.796 & 0.522 & 0.518 & 0.372 & 0.528 & & \\
\hline I & -0.384 & -0.493 & -0.509 & -0.598 & 0.702 & 0.717 & 0.603 & 0.726 & 1.000 & \\
\hline UB & -0.019 & -0.444 & -0.171 & -0.300 & 0.787 & 0.836 & 0.756 & 0.840 & & \\
\hline LB & -0.785 & -0.746 & -0.780 & -0.859 & 0.724 & 0.639 & 0.621 & 0.698 & 0.721 & \\
\hline $\mathbf{L}$ & -0.560 & -0.697 & -0.552 & -0.709 & 0.854 & 0.798 & 0.804 & 0.835 & 0.848 & 1.000 \\
\hline UB & -0.250 & -0.169 & -0.228 & -0.471 & 0.918 & 0.888 & 0.899 & 0.913 & 0.916 & \\
\hline
\end{tabular}

Bootstrap with 1000 replicates, using $R$ package by Herve' (2015)

Note: $\mathrm{LB}=$ Lower Bound, UB =Upper Bond, $\mathrm{A}=$ taxicab Bentham, $\mathrm{B}=$ Euclidean Bentham, $\mathrm{C}=$ taxicab Rawls, D=Euclidean Rawls, E= Freedom to make life choices 2008-2015, F= Democratic Quality 2008-2014, G=World Happiness Index 2016, H= Voice Index WB, I=BOD BLI, L=Average BLI 
Figure 1 relation between the societal loss functions of BLI and 'Freedom to make life choices' (The cross represents the median values)
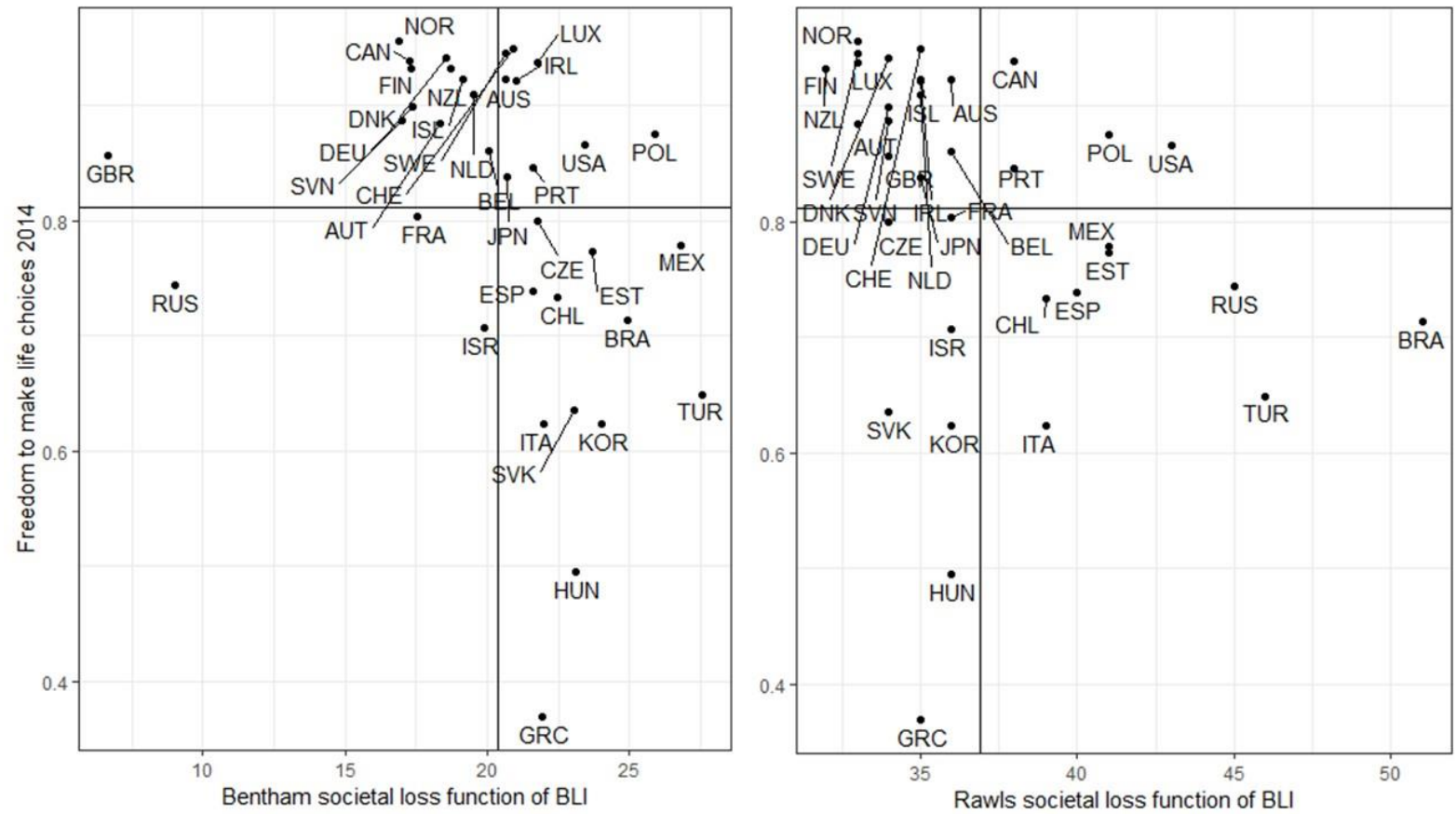

Figure 2 relation between the societal loss functions of BLI and 'Democratic Quality' (The cross represents the median values)
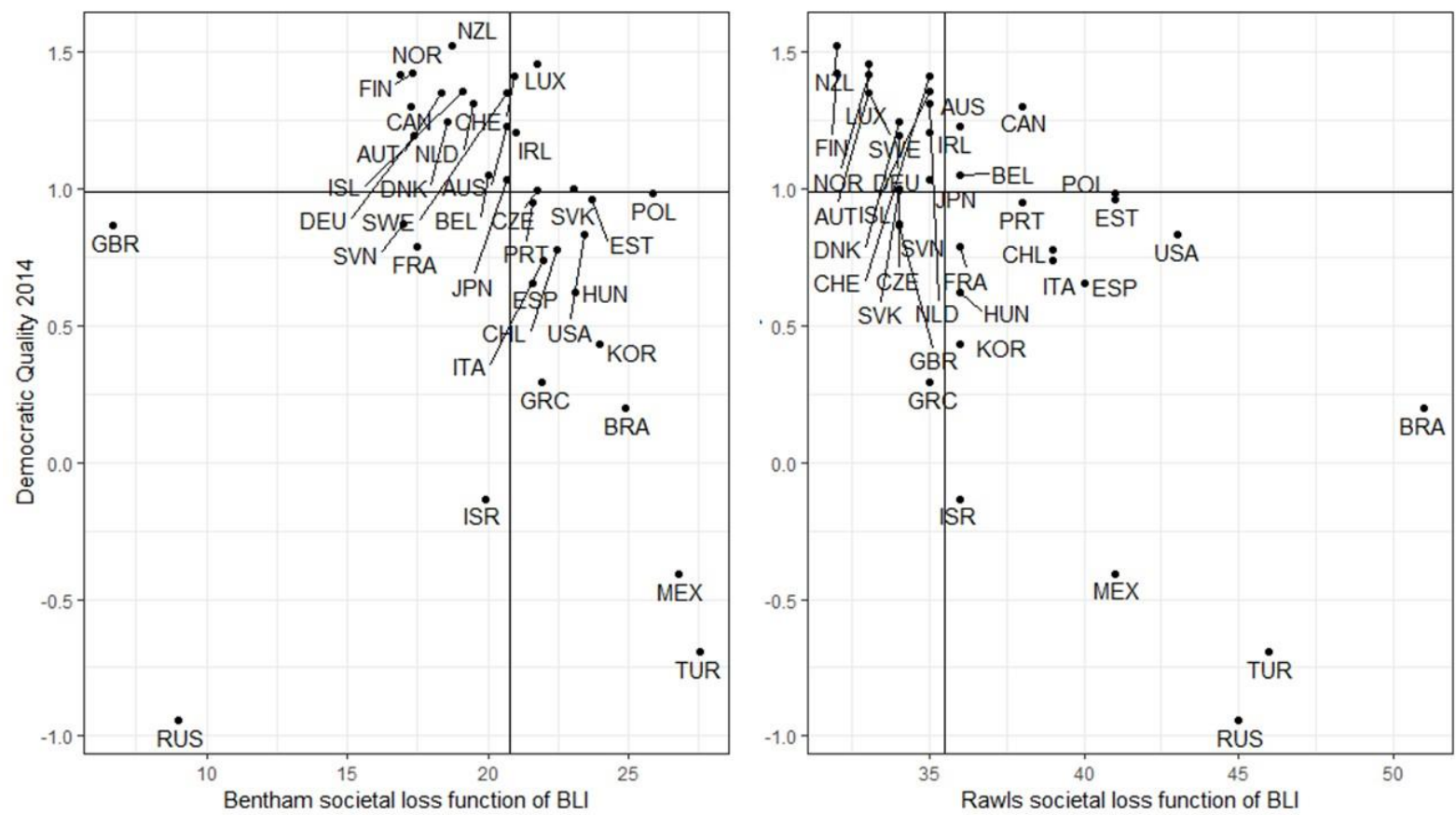
Figure 3 relation between the societal loss functions of BLI and 'Voice Index' (The cross represents the median values)
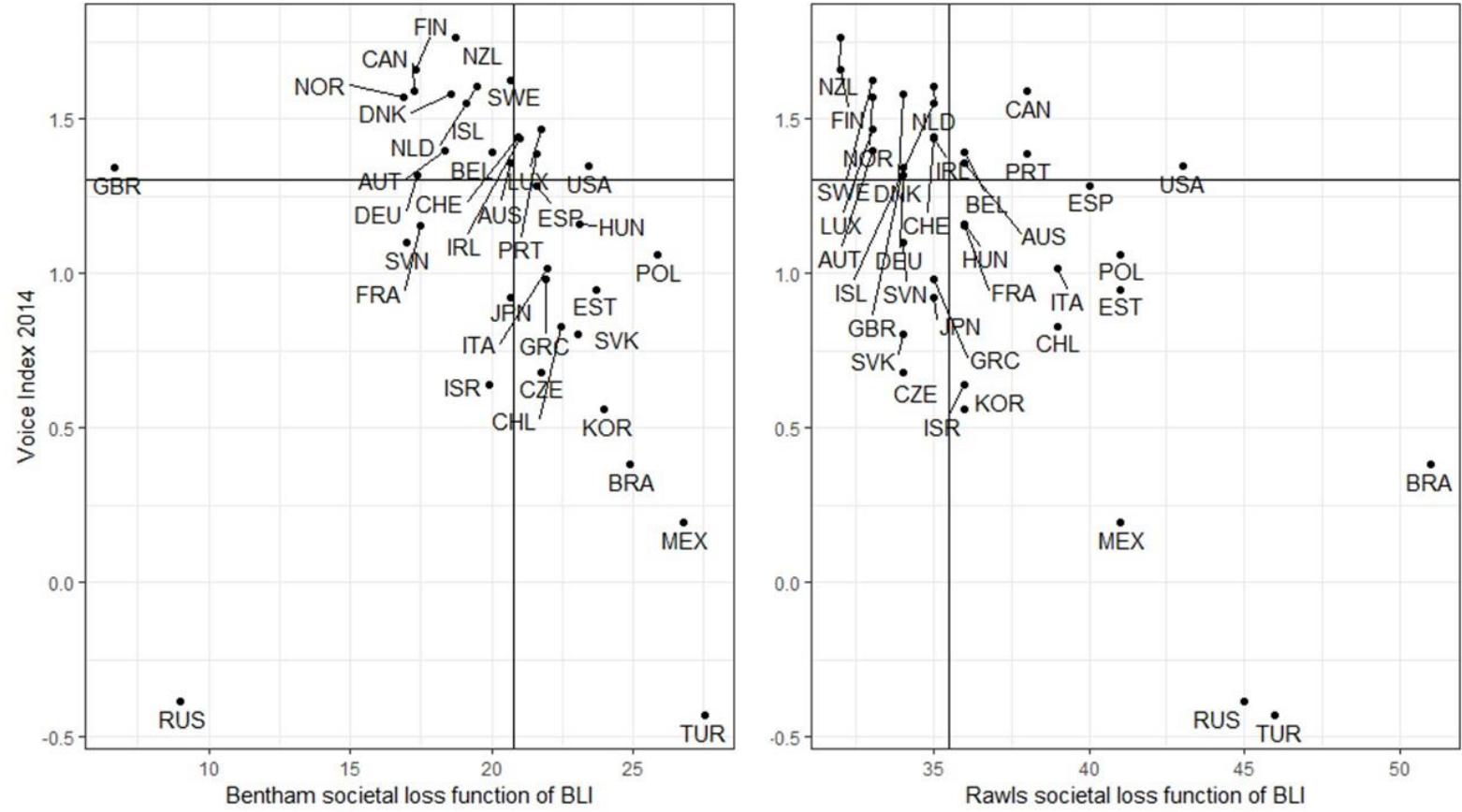

Figure 4 relation between the societal loss functions of BLI and the average BLI' (The cross represents the median values)
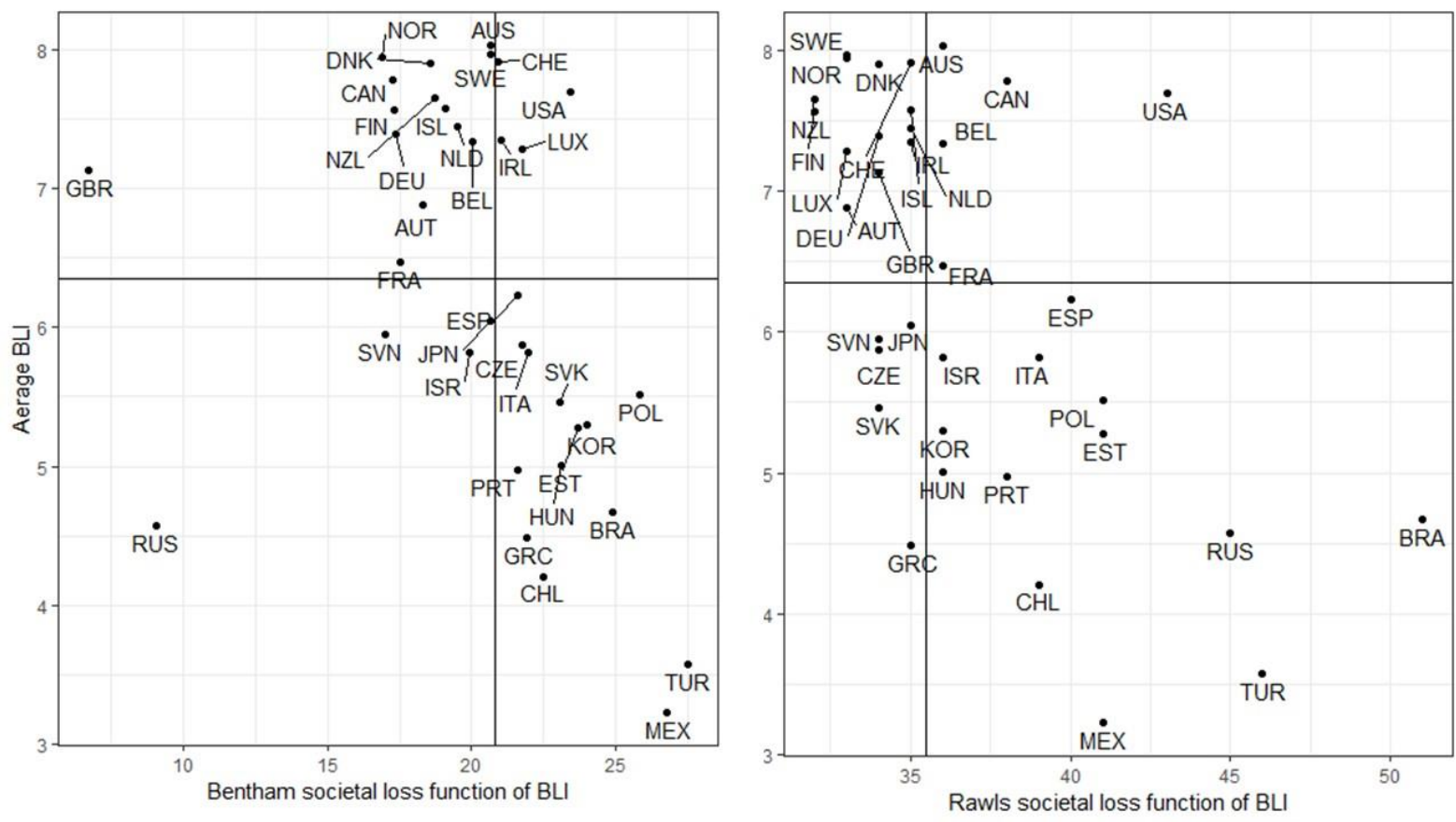